\title{
EDUCANDO PARA SUSTENTABILIDADE AMBIENTAL
}

\section{ARTIGO DE REVISÃO}

SOARES, Simone Cesario ${ }^{1}$

ROESLER, Marli Renate von Borstel ${ }^{2}$

SOARES, Simone Cesario. ROESLER, Marli Renate von Borstel. Educando para sustentabilidade ambiental. Revista Científica Multidisciplinar Núcleo do Conhecimento. Ano 05, Ed. 11, Vol. 10, pp. 118-128. Novembro de 2020. ISSN: 24480959, Link de acesso:https://www.nucleodoconhecimento.com.br/educacao/sustentabilidadeambiental

\section{RESUMO}

A sociedade atual precisa criar mecanismos de desenvolvimento global baseados no respeito pela natureza, nos direitos humanos universais, na justiça econômica. A sustentabilidade visa a partir de uma conformidade entre a humanidade e a natureza, relacionado ao impacto das atividades econômicas no meio ambiente e dessa relação, a busca pela qualidade de vida dessa geração, e das futuras. Este artigo busca

${ }_{1}^{1}$ Mestrado em andamento em Desenvolvimento Rural Sustentável. Especialização em A Moderna Educação: metodologias, tendências e foco no aluno. Especialização em Gestão Escolar. Especialização em Especialização em Arte Educação. Especialização em Especialização em Lingua Espanhola. Graduação em Pedagogia. Graduação em Artes - Educação Artística. Graduação em Filosofia Bacharelado. Graduação em Filosofia - Licenciatura.

${ }^{2}$ Orientadora. Doutorado em Serviço Social. Mestrado em Educação. Especialização em Antropologia. Especialização em Vertentes Teór Metod Contemp e Implic Serv Socia. Especialização em Saúde Pública. Aperfeiçoamento em Metodologia da Pesquisa em Ciências Sociais. Graduação em Serviço Social. 
compreender o currículo escolar da educação básica atrelada a prática do ensino para a sustentabilidade, tendo em vista o mundo atual. Objetiva-se uma reflexão a respeito do currículo escolar, tendo em vista as transformações profundas promovidas, por novos meios de produção e por novas formas de pensar o mundo e das demandas educacionais, destacando o papel da educação no contexto ambiental na busca por uma aprendizagem para a vida, ou seja, para sustentabilidade ambiental e do nosso desenvolvimento sustentável.

Palavras-chave: Educação-ambiental, sustentabilidade, Políticas-Públicas.

\section{INTRODUÇÃO}

Uma das funções da escola é a de ensinar e refletir as práticas sociais, e nesse contexto o mundo que tem sido marcado pela degradação permanente do meio ambiente e do seu ecossistema, no qual envolve uma necessária articulação com a produção de sentidos sobre a educação ambiental e para a sustentabilidade.

E diante desta nova exigência de habilidades, valores e principalmente postura crítica em relação aos problemas e aos desafios postos pela sociedade, a questão ambiental e da sustentabilidade é e será um grande desafio desse mundo globalizado. Uma vez que a qualidade de vida principalmente das futuras gerações estará mais dependente do que nunca deste fator. E como a escola pode atuar diante deste desafio?

O conceito de Desenvolvimento Sustentável ganhou evidência segundo Boff (2017) principalmente a partir da Conferência de 1972, a partir do Relatório de Brundtland, publicado em 1987. Desenvolvido pela Comissão Mundial, este relatório integra-se em um conjunto de iniciativas que ressaltam uma visão crítica do modelo de desenvolvimento adotado por países industrializados e reproduzido por nações em desenvolvimento, bem como destacam os riscos do uso excessivo dos recursos naturais, desconsiderando a capacidade de suporte dos ecossistemas.

O desenvolvimento deve satisfazer as necessidades presentes, e ao mesmo tempo não comprometer a capacidade das gerações futuras (GUIMARÃES, 2007; BOFF, 2017; GIL et al., 2019). 


\section{METODOLOGIA}

O presente artigo foi desenvolvido a partir da revisão de artigos científicos, da literatura existente acerca da temática educação, contextualizando as recentes discussões acerca das profundas transformações vividas pela sociedade contemporânea. Assim este trabalho se propõe a discutir e refletir acerca das questões educacionais da atualidade, ou seja, como a escola vem tratando de temas de interesse social e coletivo, como a sustentabilidade.

\section{RESULTADOS E DISCUSSÃO}

A partir da necessidade de pensar sobre a questão da sustentabilidade no meio escolar, a fim de que a mesma possa ser considerada um ambiente sustentável, o Ministério da Educação (MEC) recomenda que essa instituição deve estabelecer uma relação entre o currículo, a gestão e o espaço físico, desenvolvendo propostas pedagógicas que visam o aprendizado, o pensamento e a ação, de modo a estimular um futuro com criatividade, inclusão, liberdade e respeito aos direitos humanos e as diferenças, além do cuidados com os outros, com a natureza e com o ambiente de modo intencional adotando uma postura coesa em discurso e práticas. (BRASIL, 2012b).

A questão ambiental configura-se como algo crescentemente que envolve um conjunto de atores do universo educativo, potencializa o engajamento dos diversos sistemas de conhecimento; a capacitação de profissionais numa perspectiva interdisciplinar e de interesse social. Nesse contexto, o conhecimento deve priorizar as relações entre o meio natural e social, além de considerar o papel dos diversos atores na busca por um desenvolvimento socioambiental.

Nesse sentido, a escola, sendo um espaço social e de aprendizado, contribui para a formação de cidadãos conscientes, críticos, responsáveis e atentos à relação homemambiente. Por isso, a educação ambiental tornou-se um componente essencial no processo de formação, visto que comunga com todos os seguimentos e currículos escolares. Por se tratar de uma temática interdisciplinar, ela precisa ser desenvolvida 
de forma contínua, permanente, sistemática e transversal, contextualizando tais conteúdos com a realidade integral do mundo contemporâneo.

Assim sendo:

O desenvolvimento de programas de Educação Ambiental e a conscientização de seus conteúdos dependem deste complexo processo de emergência e constituição de um saber ambiental, capaz de ser incorporado às práticas docentes e como guia de projeto de pesquisa (LEFF, 2018, p. 218).

O que se percebe atualmente na escola é o ensino da educação ambiental dentro de uma modalidade formal, com predominância de alguns temas como, por exemplo, lixo, proteção do verde, uso e degradação dos mananciais e ações para conscientizar a população em relação à poluição do ar.

O grande desafio da escola no contexto ambiental é o de viabilizar as práticas educativas, articulando o ensino em sua prática diária; no sentido de enfrentar uma degradação ambiental junto aos problemas sociais.

Atualmente, a Educação Ambiental tem ganhado grande relevância principalmente no contexto educacional por consequência das políticas de impacto estimuladas no mundo e da sucessão de medidas ambientais em âmbito internacional. No Brasil, a Educação Ambiental parece ser um tema novo e que por vezes não tem apresentado objetivo e metodologias de ação estabelecidas nas escolas (Bernardes e Prieto, 2010).

Ao mesmo tempo em que se fazem importantes os problemas ambientais da comunidade, eles devem ser analisados e o aluno precisa perceber que faz parte da sociedade. A educação ambiental deve compreender a estreita interação entre Meio Ambiente equilibrado e a qualidade de vida do homem, além de, mostrar que ela não se limita à preservação do Meio Ambiente, mas incorpora os aspectos sociais, econômicos, éticos e políticos.

A conexão, entre as propostas curriculares educacionais e as políticas que envolvem a Educação Ambiental e Sustentável, pode ser encarada como um dos fatores que 
dificultam os resultados esperados em prol da exploração da dimensão ambiental nas práticas escolares, pois nessa perspectiva, "o debate ambiental adquire uma dimensão pedagógica e política na medida em que oportuniza o debate, o questionamento e a negociação de projetos políticos, culturais e sociais" (TORALES, 2013, p. 2).

A educação exerce um papel muito importante na vida das futuras gerações. Neste sentido, a Comissão Internacional sobre a Educação para o século XXI, Organização das Nações Unidas para a Educação, a Ciência e a Cultura (UNESCO), compreende que é fundamental a capacidade de inovação e que depende da autonomia da educação no ensino e na participação de seus agentes locais, na capacidade de transformação em sua estrutura, em seu modo de pensar, planejar e gerir na educação básica. E nessa perspectiva, abrindo espaço para um novo currículo, baseado em novas metodologias fundamentado na cidadania e na sustentabilidade.

A educação ambiental vai muito além do seu conservadorismo. Trata-se de uma mudança radical de mentalidade em relação à qualidade de vida, que está diretamente ligado ao tipo de convivência que mantemos com a natureza e que implica atitudes, valores e ações. Trata-se de uma opção de vida por uma relação saudável e equilibrada, com o contexto, com os outros, com o ambiente mais próximo, a começar pelo ambiente escolar, de trabalho e doméstico (GADOTTI, 2009, p 96).

De acordo com a Política Nacional de Educação Ambiental (PNEA), Lei n 9.795/1999, a Educação Ambiental tem por objetivo formar cidadão que se defronta com a problemática do meio ambiente, que é capaz de perceber pontos críticos, de pensar a coletividade; se posicionando frente aos desafios presentes nos locais em que vive (BRASIL, 1999).

Tendo em vista esse contexto no ano de 1996, o Ministério da Educação (MEC), "elaborou os Parâmetros Curriculares Nacionais (PCNs) incorporando a dimensão ambiental, como Tema Transversal, nos currículos de Ensino Básico". Assim, essa incorporação buscou pôr fim uma perspectiva conteudista, na qual ainda persiste na educação brasileira. (SANTOS, 2013, p. 2) 
A inclusão da Educação Ambiental nos PCNs apresenta uma perspectiva integradora e transformadora que, no entanto, metodologicamente, carece de uma indicação menos subdividida dos conteúdos das diferentes áreas do conhecimento; que poderia ocasionar uma mudança das práticas pedagógicas na Educação Ambiental (SOUZA, 2004).

Leff afirma que a escola é um dos elementos para que a educação ambiental se efetive, mas diz que também:

Os princípios da gestão ambiental e da democracia participativa propõem a necessária transformação dos Estados nacionais e da ordem internacional para uma convergência dos interesses em conflitos e dos objetivos comuns dos diferentes grupos e classes sociais em torno do desenvolvimento sustentável e da apropriação da natureza. O fortalecimento dos projetos de gestão ambiental local e das comunidades de base está levando os governos federais e estaduais, como também os municipais, a instaurar procedimentos para dirimir pacificamente os interesses de diversos agentes econômicos e grupos de cidadãos na resolução de conflitos ambientais, através de um novo contrato social entre o Estado e a sociedade brasileira. (2018, p.61-62)

Considerando a importância da educação ambiental e da visão de integração do mundo, no tempo e no espaço, a escola deve oferecer métodos efetivos para a compreensão e aplicação da educação ambiental.

A Carta de Belgrado considera como objetivos da educação ambiental:

Tomada de consciência: Ajudar às pessoas e aos grupos sociais a adquirir maior sensibilidade e consciência do meio ambiente em geral e dos problemas. Conhecimentos: Ajudar às pessoas e aos grupos sociais a adquirir uma compreensão básica do meio ambiente em sua totalidade, dos problemas associados e da presença e função da humanidade neles, o que necessita uma responsabilidade crítica. Atitudes: Ajudar às pessoas e aos grupos sociais a adquirir valores sociais e um profundo interesse pelo meio ambiente que os impulsione a participar ativamente na sua proteção e melhoria. Aptidões: Ajudar às pessoas e aos grupos a adquirir as aptidões necessárias para resolver os problemas ambientais. Capacidade de avaliação: Ajudar às pessoas e os grupos sociais a avaliar as medidas e os programas de educação ambiental em função dos fatores ecológicos, políticos, sociais, estéticos e educativos. Participação: Ajudar às pessoas e aos grupos sociais a desenvolver seu sentido de responsabilidade e a tomar consciência da urgente 
necessidade de prestar atenção aos problemas ambientais, para assegurar que sejam adotadas medidas adequadas (1975, p. 2-3).

Partindo das premissas da Carta de Belgrado, a escola é um espaço de formação e transformação que deve garantir que os seus objetivos sejam atingidos, viabilizando e consolidando na prática cotidiana dos educandos; bem como discutidos com a comunidade. Sendo no espaço escolar, é necessário tratar de temas da atualidade aplicados à realidade dos seus alunos. Os Parâmetros Curriculares Nacionais, do tema transversal Meio Ambiente estabelecem que:

Temas da atualidade, em contínuo desenvolvimento, exigem uma permanente atualização; e fazê-lo junto com os alunos é uma excelente oportunidade para que eles vivenciem 0 desenvolvimento de procedimentos elementares de pesquisa e construam, na prática, formas de sistematização das informações, medidas, considerações quantitativas, apresentação e discussão de resultados. O papel dos professores como orientadores desse processo é de fundamental importância. Essa vivência permite aos alunos perceber que a construção e a produção dos conhecimentos são contínuas e que, para entender as questões ambientais, há necessidade de atualização constante. (BRASIL, 1997, p. 188).

No século $X X$, o capitalismo passou a ser mais observado em relação à sociedade de consumo, vista como dos principais problemas da sociedade moderna, uma das causadoras de impactos ambientais, gerando preocupação as gestões urbanas e implicando na busca da sustentabilidade.

O capitalista e industrial trouxeram desenvolvimento econômico e social, assim sendo, representantes de uma sociedade de consumo, com a oferta de empregos, e por consequência a geração de renda, conforme Portilho:

A abundância dos bens de consumo continuamente produzidos pelo sistema industrial é considerada, frequentemente, um símbolo da performance bem-sucedida das economias capitalistas modernas. No entanto, esta abundância passou a receber uma conotação negativa sendo objeto de críticas que consideram o consumismo um dos principais problemas das sociedades industriais modernas. A partir da construção da percepção de que os atuais padrões de consumo estão nas raízes da crise ambiental [...] (2010, p. 67)

Sobre sociedade de consumo, dispõe Portilho: 
O consumidor de hoje é diferente dos consumidores das outras fases da sociedade moderna. Esse estilo de vida baseado na capacidade e na vontade de consumir revela-se como um livre exercício da vontade, onde Evento: XXII Jornada de Pesquisa os consumidores se sentem no comando. Assim, a Sociedade de Consumo pode ser definida a partir não só das diferenças na maneira como as pessoas satisfazem suas necessidades, mas também das diferenças nos sonhos, esperanças e aspirações [...] (2010, p. 76-77).

Ao implementar a educação ambiental, estará facilitando aos alunos e a comunidade em geral uma compreensão dos problemas existentes, da presença humana no meio ambiente, da sua responsabilidade e do seu papel crítico como cidadão de um país e de um planeta. Desenvolvendo assim, competências e valores que conduzirão a repensar e avaliar de diversas maneiras as nossas atitudes e as consequências ao meio ambiente.

Diante da crescente transformação da consciência ambiental voltada para a racionalidade e ao senso crítico; que integre às formas pedagógicas, Leff nos ajuda no caminho para agregar valor às práticas da educação ambiental. Assim, é proposto a repensar "o programa positivista, obcecado pela unidade das ciências e unificação do conhecimento" (LEFF. 2008. p. 258-259). Propondo assim, a saída dos meios pedagógicos tradicionais e a inserção em um ambiente extraescolar ou até mesmo extracurricular; uma vez que os currículos formais não dariam conta desta nova racionalidade.

Nesse contexto, segundo Reigota (1998), a educação ambiental aponta para uma nova proposta pedagógica centrada na conscientização, na mudança de comportamento, no desenvolvimento das competências. Para Pádua e Tabanez (1998), ela propicia o aumento de conhecimentos, mudanças de valores e aperfeiçoamento de habilidades e condições básicas para estimular a integração e harmonia dos indivíduos com o meio ambiente.

A relação da educação e o meio ambiente assume um desafio cada vez maior, demandando a emergência de novos saberes para aprender processos sociais que se complexificam e riscos ambientais que se intensificam. E ao mesmo tempo cabe a 
escola a criação desse elo com as novas gerações, pois o tempo escolar é um diálogo de gerações conforme análises dos autores: Carr (2011) e Sidnei Oliveira (2010).

A educação como principal propulsor da mudança, necessita de novos métodos de ensino, colocando o estudante em contato com o ambiente externo à sala de aula, em contato direto com a natureza. Aproveitando o conhecimento popular, para potencializar a sustentabilidade local e regional (BOFF, 2017).

Desta forma, como estabelecido pela lei (9795/99), a Educação Ambiental deve ser desenvolvida como uma prática educativa coesa, contínua e permanente em cada nível e modalidade do ensino formal, e não apenas como uma disciplina específica integra o currículo escolar.

As escolas do Brasil, principalmente as públicas, enfrentam problemas, para a realização de atividades práticas, seja por falta de infraestrutura, falta de espaço, recursos humanos, insumos e até mesmo de interesse. Ao trabalhar os temas transversais, sugerem-se ações fora da sala de aula, ou seja, não apenas de forma expositiva, mas sim que os alunos possam ter contato com a natureza, com problemas reais, busca a resolução destas. Essa não é uma prática corrente de nossas escolas.

Não é possível humanizar o planeta sem a apropriação intelectual do espaço, sem a materialização de projetos elaborados por sujeitos históricos e sociais.

Ao reconhecer a capacidade de destruição e as marcas que vamos deixando em decorrência das nossas maneiras de estar no mundo, reconhecemos também, por oposição, o enorme potencial transformador e regenerador do qual somos dotados, principalmente quando refletimos e agimos no coletivo (BORGES, 2011, p. 15).

A educação enquanto prática ambiental, talvez seja a tarefa mais complexa a ser realizada no ambiente escolar. Pois depende de um compromisso, um engajamento Intersetorial.

\section{CONSIDERAÇÕES FINAIS}


A questão ambiental é urgente, e não se restringe às paredes escolares. Mas ela pode sim fazer a diferença na medida em conseguir dialogar com a geração que aí está, bem como com as próximas gerações, na busca pela consciência cidadã, não apenas num papel chamado currículo, ou seja, apenas na teoria que ela seja capaz de promover em suas práticas dentro e fora da escola, que vislumbra a sustentabilidade na vida de seus alunos, na construção de um muito mais justo para todos.

A escola é uma intuição social inserida numa sociedade, pela função que exerce a de formar cidadãos, de preparar para a vida e desta forma a mesma precisa integrar-se ao mundo, dialogando com as demandas vigentes, e não sendo indiferente. A demanda pela sustentabilidade ambiental é urgente e a escola pode ser a grande patrona desta empreitada, pois dela pode depender a própria sobrevivência das próximas gerações.

\section{REFERÊNCIAS}

A Carta de Belgrado. Disponível em: https://www.mma.gov.br/informma/item/8066carta-de-belgrado Acesso em: 30 abr. 2020.

Agroecologia e saber ambiental. Porto Alegre, v.02, n.1. Jan/Mar: 2006.

BERNARDES, M. B. J.; PRIETO, E. C. Educação Ambiental: disciplina versus tema transversal. Revista Eletrônica Mestrado em Educação Ambiental. V.4, jan./jul. 2010, p. 173-185.

BRASIL. Lei de Diretrizes e Bases da Educação Nacional. Lei número 9394, 20 de dezembro de 1996.

BOFF, L. Sustentabilidade: o que é: o que não é. 7 ed. Rio de Janeiro,: Vozes, 2017.

BORGES, C.; MOREIRA, T.; TRAJBER, R. Espaços Educadores Sustentáveis. Ver. Saltos para o Futuro, ano n. 7, junho, 2011. 
CARR, N. G. A Geração Superficial: o que a Internet está fazendo com nossos cérebros. Tradução Mônica Gagliotti F. Friaça. - Rio de Janeiro: Agita, 2011.

. Epistemologia ambiental. São Paulo: Cortez, 2001.

GADOTTI, M. Pedagogia da Terra. 6º edição. Editora Fundação Peirópolis Ltda. 2009.

GIL, J.D.B.; et. al. 2019. Sustainable development goal 2: Improved targets and indicators for agriculture and food security. Ambio. V.48, p.685 - 698. https://doi.org/10.1007/s13280-018-1101-4.

GUIMARÃES, M. Educação ambiental: participação para além dos muros da escola. In. TRAJBER, R.; MELLO, S.S. Vamos cuidar do Brasil: conceitos e práticas em educação ambiental na escola. Brasília: UNESCO, 2007

LEFF. E. Saber Ambiental. 11 ed. Petrópolis: Vozes, 2018.

. Ministério da Educação. Conselho Nacional de Educação Conselho Pleno Resolução № 1, de 30 maio de 2012.

- Ministério da Educação e Desporto. Secretaria de Educação Fundamental. Parâmetros Curriculares Nacionais: temas transversais. Brasília: MEC/SEF, 1997.

OLIVEIRA. S. Geração Y - o nascimento de uma nova versão de líderes. São Paulo: Integrante, 2010.

PÁDUA, S.; TABANEZ, M. (orgs.). Educação ambiental: caminhos trilhados no Brasil. São Paulo: Ipê, 1998.

PORTILHO, F. Sustentabilidade Ambiental, Consumo e Cidadania. São Paulo: Cortez, 2010. 
. Presidência da República. Casa Civil. Lei 9.795/99. Dispõe sobre a Educação Ambiental, institui a Política Nacional de Educação Ambiental e dá outras providências. Disponível em: http://www.planalto.gov.br/ccivil_03/Leis/L9795.htm

REIGOTA, M. Desafios à educação ambiental escolar. In JACOBI, P. et al. (orgs). Educação, meio ambiente e cidadania: reflexões e experiências. São Paulo: SMA, 1998. P.43-50.

REIGOTA, M. Meio Ambiente e Representação Social. São Paulo: 8 ed. Cortez, 2010. p. 87.

Saber Ambiental: sustentabilidade, racionalidade, complexidade, poder. 2 ed. Petrópolis: Rio de Janeiro: Vozes, 2014.

SANTOS, T. C. dos; COSTA, M. A. F. da. A Educação Ambiental nos Parâmetros Curriculares Nacionais. In: Atas do IX Encontro Nacional de Pesquisa em Educação em Ciências. Águas de Lindóia, SP. Novembro de 2013

SOUZA, D. A. A Relação da Criança com o Meio Ambiente: A Educação Ambiental nos Contextos Escolares. 2004. 143p. Dissertação (Mestrado em Educação) - Instituto Superior de Estudos Pedagógicos, Rio de Janeiro, 2004.

TORALES, M.T. A Inserção da educação ambiental nos currículos escolares e o papel dos professores: da ação escolar a ação educativo-comunitária como compromisso político pedagógico. Revista do PPGEA/ FURG - Rio Grande do Sul,

Enviado: Setembro, 2020.

Aprovado: Novembro, 2020. 